Disponível em

http://www.anpad.org.br/rac

RAC, Rio de Janeiro, v. 19, n. 2, art. 2, pp. 193-211, Mar./Abr. 2015 http://dx.doi.org/10.1590/1982-7849rac20151171

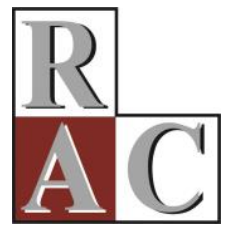

(oc) BY-NC

\title{
Avaliação do Risco Regulatório em Pesquisa \& Desenvolvimento no Setor Elétrico Brasileiro
}

Regulatory Risk Assessment of Research \& Development in the Brazilian Electrical Sector

José Luiz Pereira Brittes Universidade Estadual de Campinas - UNICAMP

Sergio L. M. Salles-Filho Universidade Estadual de Campinas - UNICAMP

Mariana Savedra Pfitzner Universidade Estadual de Campinas - UNICAMP

Artigo recebido em 12.11.2012. Última versão recebida em 24.10.2014. Aprovado em 26.10.2014. 


\title{
Resumo
}

$\mathrm{O}$ artigo propõe metodologia de avaliação ex-ante de projetos de P\&D\&I do setor elétrico, incorporada a uma ferramenta de análise multicritério, com foco em risco. A P\&D do setor elétrico é regulada pela Agência Nacional de Energia Elétrica (ANEEL) e obriga as empresas a investirem parte de sua Receita Operacional Líquida (ROL) em P\&D\&I. A imposição de P\&D\&I ao setor levou suas empresas a buscarem formas de alocar recursos em projetos que tentam harmonizar o contexto regulatório com seus direcionadores de mercado, forçando-as a estruturarem em suas rotinas uma gestão da inovação que mitigasse riscos regulatórios. Uma forma de se viabilizar essa mitigação é o uso de metodologias de seleção de projetos capazes de ponderar múltiplos elementos, de certo modo, antagônicos. A PiTech, Prioritization in Technology, é uma ferramenta de análise multivariada paramétrica, flexível e propícia a essa ponderação. Neste artigo, aplicaram-se critérios operacionais, mercadológicos e regulatórios, em múltiplas combinações, para 19 projetos de um grupo empresarial de energia elétrica. A ferramenta mostrou-se útil ao permitir aos tomadores de decisão verificarem a pertinência de investimento em 16 projetos, totalizando $\mathrm{R} \$ 61$ milhões em 2010, com riscos de glosa minimizados e concomitante aderência a interesses empresariais.

Palavras-chave: P\&D\&I no setor elétrico; regulação econômica; avaliação de risco.

\begin{abstract}
This paper presents a methodology of R\&D\&I project ex-ante evaluation for the Brazilian electric power sector using a multi-criteria tool focused on risk. The R\&D process in the Brazilian electric power industry is regulated by the National Electric Energy Agency (ANEEL), and requires companies to invest part of Net Operating Income (NOI) in R\&D\&I. This pushed firms to structure management routines for technological innovation efforts that simultaneously mitigate market and regulatory risk. One way to achieve this issue is to perform an ex-ante evaluation project selection methodology able to deal with somewhat antagonistic multiple-element analysis. PiTech (Prioritization in Technology) is a very flexible and conducive tool for performing such a weighted parametric multivariate analysis. The case presented in this article was performed with PiTech working with operational, market and regulatory criteria in multiple combinations for 19 projects for a key holding group in the Brazilian power market. The tool proved to be very useful by allowing decision makers to verify the appropriateness of investment in $\mathrm{R} \& \mathrm{D}$ projects totaling $\mathrm{R} \$ 61$ million in 2010 , minimizing regulatory risks and preserving adherence to corporate interests.
\end{abstract}

Key words: R\&D\&I in the electrical sector; economic regulation; risk assessment. 


\section{Introdução}

As empresas têm motivações naturais para inovar, relacionadas à redução de custos e à diferenciação da concorrência, sendo que retornos econômico-financeiros são condições necessárias para o agente inovador (Gilbert, 2006; Organization for Economic Cooperation and Development [OECD], 2005). Segundo a teoria schumpeteriana, setores com estrutura monopolista tendem a ser mais inovadores que setores de concorrência perfeita, pois tais empresas precisam garantir sua posição monopólica no mercado e, assim, conseguem se apropriar de benefícios da inovação. Os monopólios não naturais são uma consequência da inovação bem sucedida, por gerarem lucros extraordinários e resultados de difícil imitação (Laino, 2011); essa regra, porém, nem sempre se aplica a monopólios naturais regulados, típicos das indústrias de rede. Isso porque tais indústrias passam a assumir a posição de únicas produtoras, em função das economias de escala, dos altos custos afundados (sunkcosts) e da ação reguladora do governo. Portanto, em monopólios naturais regulados, a falta de competição pode inibir as empresas a fazerem inovação, especialmente disruptiva (Arrow, 1962; Christensen, 2000; Leite, Albuquerque, \& Leal, 2007).

De maneira geral, a regulação busca corrigir as falhas de mercado através de ações tomadas pelos órgãos reguladores, que consistem no controle sobre preços, lucros, produção, qualidade, relações de trabalho e demanda (Stigler, 1971). Para que os monopólios naturais inovem, é também necessária a intervenção governamental por meio da regulação econômica. Essa última deve ser entendida como um conjunto de mecanismos que induzem as ações dos agentes para atividades de inovação, através, por exemplo, da obrigatoriedade de investimento em atividades de P\&D\&I ou da criação de novos produtos e serviços (Business Enterprise \& Regulatory Reform [Berr], 2008).

Enquanto a regulação pressupõe instrumentos de coerção, a inovação requer flexibilidade e certa liberdade de criação. A regulação objetiva trazer estabilidade para as relações econômicas, enquanto a inovação evoca o desenvolvimento da economia pela destruição criadora. Quando mercados e setores nascem a partir desse processo de permanente destruição e criação, a regulação se faz necessária para trazer novamente o equilíbrio.

O setor elétrico brasileiro se caracteriza como monopólio natural, sendo regulado pela Agência Nacional de Energia Elétrica (ANEEL), criada em 1995. Desde a privatização do setor elétrico na década de 90 , as distribuidoras de energia assumiram a obrigação de investir parte da ROL em P\&D, através de cláusulas presentes nos contratos de concessão. Em 2000, com a Lei n. 9.991, inaugurou-se no Brasil o marco legal do Programa de P\&D da ANEEL. Desde então, todas as empresas de geração, transmissão e distribuição foram inseridas nas atividades de P\&D. Com isso, criaram-se redes de parcerias com empresas de base tecnológica e núcleos de pesquisa de ICTs (Instituições de Ciência e Tecnologia). Internamente, as empresas viram-se obrigadas a estruturar áreas de gestão de P\&D e Inovação (P\&D\&I), para que pudessem gerir todo o processo de inovação, desde a captação de ideias até a avaliação dos resultados tecnológicos e benefícios econômicos. Por outro lado, a obrigatoriedade do investimento trouxe para as concessionárias os custos de conformidade - relacionados ao ônus de inovar - e o risco regulatório.

Desde então, além do risco inerente à inovação, o risco regulatório precisava também ser avaliado e mitigado. Este significa possíveis sanções que as concessionárias poderiam sofrer, caso não cumprissem os requisitos do Programa referentes a prazos, valores mínimos de investimento, razoabilidade de custos dos projetos e qualidade de resultados, descritos nos manuais da ANEEL de 2001, 2006, 2008a e 2012. Assim, essas empresas eram obrigadas a aplicar anualmente um montante mínimo em projetos de $\mathrm{P} \& \mathrm{D}$ com mérito técnico-científico e outros resultados esperados pelo órgão regulador; caso contrário, se esses resultados não fossem comprovados, elas sofreriam glosa de investimento ou multa.

Até 2008, os projetos de P\&D eram aprovados pela ANEEL antes de se iniciarem. O órgão regulador era, em princípio, corresponsável pela aplicação dos recursos e por seus resultados. Ao final, eles eram fiscalizados sob as perspectivas da prestação de contas e da aferição dos resultados 
tecnológicos alcançados. Com o marco regulatório de 2008, os projetos passaram a não mais ser aprovados ex-ante pela ANEEL. Requisitos relacionados ao mérito técnico-científico dos projetos (originalidade, relevância, aplicabilidade e razoabilidade de custos) passaram a ser avaliados somente após sua conclusão (ANEEL, 2008a). O fato de o órgão regulador ter se eximido da responsabilidade de aprovar os projetos ex-ante deixou nas mãos das concessionárias de energia a responsabilidade da aplicação dos recursos do Programa e de seus resultados, o que aumentou o risco regulatório para elas. Destarte, tornou-se premente para as empresas a avaliação sistemática de projetos de P\&D\&I considerando o risco regulatório como fator crítico, além dos riscos inerentes à inovação (tecnológico e de mercado).

O objetivo deste artigo é refletir sobre a evolução do marco regulatório no setor elétrico brasileiro e analisar uma metodologia de avaliação e mitigação do risco de projetos de P\&D\&I aplicando essa metodologia a um caso de empresa que atua no setor. Esta metodologia converteu-se em uma ferramenta computacional de apoio à decisão e à avaliação ex-ante de projetos do Programa da ANEEL (Prioritization in Technology [PiTech]), a qual vem sendo usada desde 2010 pela empresa pesquisada. Assim, este artigo traz duas contribuições para os campos da economia e de gestão da tecnologia, na medida em que propõe uma reflexão histórico-institucional do marco regulatório da P\&D\&I, ao mesmo tempo em que apresenta os princípios construtivos de uma ferramenta de avaliação de risco que surgiu como resposta para mitigar o risco regulatório.

A segunda seção descreve a metodologia utilizada neste trabalho. Pesquisas de caráter bibliográfico e documental foram feitas para responder a questão: Dado o contexto institucional que obriga as empresas de energia elétrica a investirem em P\&D\&I, como se devem selecionar os projetos de P\&D\&I ex-ante, de modo a se mitigar o risco regulatório e atender aos interesses empresariais?

A pesquisa bibliográfica buscou os nexos teóricos entre inovação e regulação (Almeida \& Ohayon, 2009; Berr, 2008; Blind, 2012; Walz, Schleich, \& Ragwitz, 2008), assim como o levantamento de metodologias de apoio à decisão e ao gerenciamento de risco de projetos (Clark \& Wheelright, 1993; Cooper, 2007; Cooper, Edgett, \& Kleinschmidt, 2002; International Organization for Standardization [ISO], 2009a; Mustafa \& Al-Bahar, 1991; Oliveira \& Rosenfeld, 2011; Roy \& Bouyssou, 1993), detalhados na terceira seção. Por sua vez, essas metodologias podem ser aplicadas antes ou durante a execução dos projetos de P\&D\&I para minimizar o risco, a exemplo de stage-gates, funil de inovação, análise financeira e análise multicritério.

A quarta seção descreve uma visão da evolução da P\&D\&I do setor, regida pelo Programa da ANEEL, em quatro fases, bem como apresenta os resultados da aplicação da ferramenta numa empresa de energia elétrica, considerando a avaliação de seleção de projetos.

A aplicação da ferramenta na avaliação de projetos de P\&D\&I agrupa os critérios em três dimensões analíticas, a saber, mercadológica, operacional e regulatória. A dimensão mercadológica inclui critérios que avaliam o risco de mercado e os benefícios do projeto para a empresa; a operacional abarca um conjunto de atributos responsável por avaliar a execução e o risco tecnológico. A dimensão regulatória, fundamental para a adequada utilização dos recursos do Programa da ANEEL, mede o risco regulatório dos projetos. A PiTech apresenta como avanço a possibilidade de avaliação dos riscos de maneira combinada entre as dimensões, isto é, os projetos são alocados em diversas áreas de interesse. Por exemplo, alguns projetos avaliados são lotados na área de intersecção entre a dimensão regulatória e a de mercado, atendendo tanto aos interesses da empresa como aos da ANEEL. E, de posse dos resultados da avaliação, a concessionária decide se executa ou não os projetos com recursos do Programa da ANEEL e/ou próprios.

As considerações finais, expostas na última seção, mostram que a PiTech, originária da necessidade de mitigar o risco regulatório nas empresas, tem se mostrado eficaz na avaliação e na priorização de projetos de P\&D do Programa da ANEEL na empresa estudada. 


\section{Metodologia}

Esta pesquisa pode ser considerada exploratória, servindo-se de procedimentos de investigação de caráter bibliográfico, documental, além do estudo de caso. Ela é exploratória porque busca o aprimoramento de ideias e a reflexão sobre um determinado fenômeno novo (Selltiz, Wrightsman, \& Cook, 1975), nesse caso traduzido através da concepção de uma ferramenta de gerenciamento de risco regulatório de projetos de $\mathrm{P} \& \mathrm{D} \& \mathrm{I}$, originada da obrigatoriedade de investimento em P\&D\&I pelas empresas de energia elétrica.

Em termos do aprimoramento de ideias, o presente trabalho contribui para o campo da gestão de tecnologia através da apresentação da lógica de operação de uma metodologia multicritério de avaliação ex-ante de projetos de $\mathrm{P} \& \mathrm{D} \& \mathrm{I}$, considerando a gestão de riscos, especialmente do regulatório, em uma empresa distribuidora de energia. Como resultado da metodologia multicritério, foi desenvolvida uma ferramenta computacional de avaliação ex-ante de projetos de P\&D\&I. Destaque-se que a ferramenta constitui uma novidade no Brasil, pois incorpora a questão da mitigação do risco regulatório nas atividades de P\&D\&I.

Através da pesquisa bibliográfica, este trabalho propõe uma contextualização teórica sobre políticas de inovação e regulação econômica (Rothwell \& Zegveld, 1988), bem como tece as distintas relações entre inovação e regulação (Almeida \& Ohayon, 2009; Berr, 2008; Blind, 2012; Walz et al., 2008), para que se compreenda a origem do risco regulatório. A pesquisa bibliográfica também possibilita o mapeamento das principais formas de gerenciamento do risco em P\&D\&I e a explicação da metodologia multicritério (Roy \& Bouyssou, 1993), que forma o princípio construtivo da ferramenta.

A pesquisa documental fundamenta-se no estudo do marco regulatório da $\mathrm{P} \& \mathrm{D}$ no setor elétrico brasileiro, por meio da consulta às Leis n. 9.991 (2000), n. 10.848 (2004), n. 11.465 (2007), à Medida Provisória 144 (2003) e aos manuais de P\&D do Programa ANEEL de 2001, 2006, 2008a e 2012. Através do manual de 2008, foram definidos importantes critérios que fazem parte da metodologia gerada e compõem as suas dimensões de análise. Como a elaboração da metodologia multicritério data de 2010, não incorpora a recente revisão do manual de 2012. Não obstante, essa revisão não altera os critérios da dimensão regulatória.

O estudo de caso na distribuidora foi essencial para o entendimento do funcionamento da metodologia e da ferramenta, permitindo também aos autores a compreensão do macroprocesso de P\&D\&I da empresa. O desenvolvimento da ferramenta PiTech é derivado de um projeto de P\&D do Programa da ANEEL, cujo objetivo circunscrevia-se ao de implantar uma metodologia multicritério de mitigação de risco regulatório para reduzir as chances de as distribuidoras terem seus projetos reprovados pela ANEEL, do ponto de vista dos critérios de avaliação previstos no Manual de 2008. Para a construção da metodologia e, consequentemente, da ferramenta PiTech, foram feitas entrevistas semiestruturadas com analistas de P\&D dessa distribuidora, e foi consultado seu Plano Diretor de P\&D\&I.

A holding, cujo valor total de P\&D\&I aplicado, de 1998 até 2014, é próximo a R \$ 230 milhões só em suas distribuidoras, tem cerca de $10 \%$ do total dos recursos empenhados no P\&D ANEEL no Brasil (ANEEL, 2013). O estudo aqui elaborado trata da carteira de projeto das distribuidoras do grupo em dezembro de 2010, no valor de R 61 milhões.

A ferramenta possui distintos níveis de agregação, sendo que cada projeto é avaliado segundo as dimensões regulatória, operacional e mercadológica. Essas e seus respectivos critérios são detalhados na quarta seção deste artigo. Eles não são independentes, em alguns casos possuem influência mútua, por exemplo, a pontuação da razoabilidade de custos depende da logística e da disponibilidade tecnológica. A metodologia da PiTech incorpora essa interdependência em seu processo de ponderação. Além disto, os critérios de uma dimensão também são usados para avaliar as outras duas restantes, embora os pesos usados na ponderação sejam diferenciados. 
Alguns dos entrevistados da distribuidora em tela já trabalhavam no setor elétrico desde o início do marco regulatório da $\mathrm{P} \& \mathrm{D}$, em 1998, permitindo o entendimento das mudanças sofridas no Programa da ANEEL desde sua concepção. Para aprofundar a análise da evolução histórico-institucional da P\&D no setor, foram entrevistados gerentes e analistas de outras concessionárias de energia indicados pelos profissionais das áreas de P\&D\&I da distribuidora em questão.

\section{Regulação Econômica, Inovação e Formas de Avaliação do Risco}

\section{Regulação e inovação}

A regulação está ligada a mecanismos coercitivos, cujos impactos visam estimular ou onerar instituições e agentes individuais (H. Q. Pinto \& Fiani, 2002; Trebing, 1984), nas esferas social, econômica, moral e cultural (Almeida \& Ohayon, 2009). No escopo deste trabalho, a regulação consiste em ações de manipulação de variáveis de mercado (preços, demanda, oferta e lucros) e sociais (organização do trabalho e requisitos de qualidade) realizadas por órgãos reguladores públicos para atingirem o equilíbrio do sistema econômico.

A regulação pode ser também utilizada pelos governos para fortalecer o processo de P\&D\&I, a competitividade global das empresas nacionais e os Sistemas Nacionais de Inovação. O processo de inovação schumpeteriano demanda esforço humano de criação, sendo que este advém das atividades sistematizadas de P\&D ou do feedback de mercado, apresentando alto nível de incerteza.

Fundamentando-se nessas definições, depreende-se que a relação entre regulação e inovação nas empresas apresenta três vetores (Almeida \& Ohayon, 2009; Berr, 2008; Bin \& Salles-Filho, 2012; Walz et al., 2008):

1. Complexidade: a regulação influencia a inovação tanto pelo lado da oferta (supply side) quanto da demanda (demand side). No primeiro caso, por exemplo, a regulação pode impactar no volume de investimentos em P\&D nas empresas. No segundo, estimula a criação de novos produtos e serviços através de restrições socioambientais, dentre outras.

2. Contradição: enquanto a regulação abrange mecanismos de coerção usados para controlar variáveis de mercado e induzir ações dos agentes econômicos, a inovação é um processo que exige flexibilidade e certo grau de liberdade criativa. Essas duas propriedades mostram-se contrárias aos mecanismos coercitivos.

3. Retroalimentação: a inovação é um processo dinâmico que transforma setores inteiros e modifica estruturas de mercado. A regulação pode vir como uma resposta às transformações provocadas pela inovação, que ocorrem quando um novo produto ou mercado surgem. Em paralelo, a inovação rompe com o equilíbrio do sistema econômico, o qual é assegurado pelos mecanismos de regulação.

De posse dessas características, conclui-se que a regulação governamental pode afetar de maneira direta o processo de inovação, ao obrigar as empresas a investirem em P\&D\&I para ampliar o progresso técnico setorial, ao induzir trajetórias tecnológicas, e, paradoxalmente, a limitar a liberdade criativa do processo. Esse quadro é particularmente comum em monopólios naturais estabelecidos por barreiras legais.

Ademais, a regulação da inovação provoca dois efeitos no ambiente organizacional. O primeiro é o de estímulo à inovação tecnológica nas empresas (efeito incitação). Estas precisam adaptar suas rotinas organizacionais, além de mobilizarem recursos humanos e materiais para gerirem a inovação. $\mathrm{O}$ segundo efeito age como um imposto (efeito imposto), no qual a obrigatoriedade de investimento atua como um ônus às organizações, trazendo os chamados custos de conformidade (compliance costs) (Blind, 2012). 
Com isso, a regulação das atividades de inovação pode ser contraproducente, na medida em que traz um ônus adicional para as organizações (a obrigação de inovar e o cerceamento da liberdade criativa), impactando principalmente em suas rotinas operacionais. Nesse sentido, incorporam-se às rotinas tanto os riscos inerentes à inovação quanto o risco regulatório. A determinação de requisitos regulatórios de agentes à margem das rotinas organizacionais pode levar à ineficiência alocativa de recursos para investimentos em $\mathrm{P} \& \mathrm{D} \& \mathrm{I}$, ao trazer às empresas o ônus de inovar.

\section{Gerenciamento de rotinas de inovação e formas de avaliação do risco}

A teoria evolucionária define rotinas como as memórias integradas à genética da empresa, as quais mantêm controle, normatização, continuidade e equilíbrio das operações executadas pelos indivíduos no ambiente organizacional (Nelson \& Winter, 1986). Ao modelar as rotinas do macroprocesso de inovação e Quadros (2008), decompõem-no em: busca de ideias; determinação da estratégia de inovação; seleção de projetos ex-ante; alocação de recursos materiais e humanos; gerenciamento do ambiente externo (parcerias); desenvolvimento e gerenciamento de projetos; implementação da inovação; e avaliação ex-post e aprendizado. Nesses modelos, o risco da inovação está embutido em todas as rotinas e, em resposta à regulação das atividades de P\&D\&I, as empresas precisam adaptar suas ferramentas e práticas a fim de gerirem a inovação e cumprirem os requisitos regulatórios.

Quando a inovação não é regulada, isto é, ocorre naturalmente em empresas que competem, os riscos associados a ela desdobram-se em tecnológicos e de mercado. Os riscos se relacionam ao insucesso do produto no mercado e/ou a entraves na rota tecnológica durante seu desenvolvimento, que, em última instância, acarretam perdas econômicas. Quando a inovação é regulada, os riscos tecnológicos e de mercado são impactados pelos requisitos que compõem o risco regulatório. Este último representa a probabilidade de o órgão regulador penalizar as organizações por não cumprirem os requisitos estabelecidos por lei referentes ao volume mínimo de investimentos, razoabilidade de custos dos projetos, prazo de entrega e qualidade dos resultados de P\&D\&I, dentre outros. Por exemplo, uma empresa cuja inovação não seja regulada pode criar novos produtos e serviços que estejam fora de seus objetivos de negócio, se estes prometerem lucros extraordinários. Empresas com inovação regulada só poderão criar novos produtos e serviços dentro dos parâmetros definidos pelo órgão regulador porque a natureza do investimento é, em geral, pública.

O gerenciamento do risco inerente à inovação pode ser efetuado através dos tradicionais métodos de stage-gate e por análise financeira (Cooper et al., 2002), funil de inovação (Clark \& Wheelwright, 1993), gráficos de frequência e checklists (Cooper, 2007; Oliveira \& Rozenfeld, 2011), os quais são aplicados durante a execução dos projetos e servem como check-points para a determinação de sua continuidade.

Todavia, projetos que possuem risco regulatório requerem também uma avaliação ex-ante para ajudar a empresa na tomada de decisão sobre executá-los ou não, respeitando as exigências do órgão regulador, já conhecidas pelo marco regulatório. Esses métodos de avaliação são objetivos e lançam mão da pontuação de critérios (análise multicritério) ou da alocação de probabilidades a eventos (simulação de Monte Carlo e análise bayesiana) (ISO, 2009b; Mustafa \& Al-Bahar, 1991; Roy \& Bouyssou, 1993). Henriksen e Traynor (1999) propõem oito métodos de avaliação de projetos de P\&D\&I, quais sejam: a revisão por pares não estruturada, modelos econômicos, programação matemática, scoring, inteligência artificial, análise de decisão, métodos interativos e otimização de portfólio.

Não obstante, os algoritmos outranking - aos quais pertencem o ELECTRE, o PROMETHEE e suas famílias respectivas - ordenam as preferências utilizando-se de atributos e restrições. López e Almeida (2014) utilizam o algoritmo PROMETHEE V para a tomada de decisão sobre a seleção de projetos de $\mathrm{P} \& \mathrm{D}$ no setor elétrico, o qual é limitado por condições como as relacionadas com a interdependência entre projetos e a disponibilidade de recursos humanos. 
A metodologia multicritério, adotada no estudo de caso em tela, é indicada para a tomada de decisões dependentes de vários atributos complexos, pressupondo uma situação de assimetria informacional e presença de múltiplos participantes do processo de avaliação. Essa metodologia possui seis passos fundamentais de execução.

No primeiro, são definidas as dimensões de análise, como mercadológica, operacional e regulatória. Após esse passo, alocam-se os atributos ou critérios de avaliação que representam de forma coerente as dimensões, a exemplo de originalidade, aplicabilidade, relevância e razoabilidade de custos. Os critérios devem ser homogêneos, isto é, não podem apresentar redundâncias entre si, devem ser comparáveis num mesmo nível hierárquico, mensuráveis, compreensíveis e úteis em relação à dimensão de análise a que se referem (Barba-Romero \& Pomerol, 1997; Keeney \& Raiffa, 1976).

O terceiro passo consiste na definição de escalas de pontuação e pesos de ponderação dos critérios. Cada critério pode ser pontuado usando-se escalas e pesos distintos, os quais variam em função da dimensão de análise. Em outros termos, um critério como originalidade pode ser usado para julgar as dimensões mercadológica e operacional com pesos diferentes. O quarto passo representa a pontuação propriamente dita dos critérios, executada pelos participantes da avaliação. Com base na pontuação atribuída e da ponderação, agregam-se os resultados numa lista de ordenamento de preferências (quinto passo). Por fim, o sexto passo é a tomada de decisão, que ocorre mediante a seleção das melhores alternativas mostradas pela lista de preferências.

\section{O Caso do Setor Elétrico Brasileiro}

\section{O contexto histórico-institucional da P\&D do setor elétrico}

Nos anos 90, o setor elétrico brasileiro passou pelos processos de privatização; desverticalização da geração, transmissão e distribuição; e introdução da competição na geração e comercialização de energia (M. S. L. Pinto \& Oliveira, 2004). Em paralelo, foram criadas instituições como a ANEEL, o Operador Nacional do Sistema Elétrico (ONS), a Empresa de Pesquisa Energética (EPE) e o Mercado Atacadista de Energia (MAE), o qual foi substituído, em 2004, pela Câmara de Comercialização de Energia Elétrica (CCEE) (ANEEL, 2008b). Por trás dessas ações, o governo brasileiro tinha como objetivos aumentar a eficiência na cadeia produtiva, modernizar a infraestrutura setorial, reduzir a dívida pública e tornar a compra e a venda de energia atrativas para potenciais investidores. A criação de uma agência reguladora independente (ANEEL) representou o fortalecimento institucional do modelo, pois suas atribuições precípuas consistem em fiscalizar as concessionárias, zelar pela qualidade do serviço prestado e mediar conflitos entre empresas e consumidores.

A despeito desses avanços, a presença de novos atores oriundos da privatização e as transformações no ambiente de negócios trouxeram o aumento da dependência tecnológica do setor em relação a sistemas e a equipamentos estrangeiros (Pompermeyer, 2009). No cenário internacional de meados dos anos 90, as empresas de energia recém-privatizadas reduziram sensivelmente seus investimentos em P\&D\&I para buscarem a eficiência operacional no curto prazo. A fim de fomentar o Sistema Nacional de Inovação, a ANEEL passou a induzir as atividades de inovação nas empresas de energia elétrica por meio da regulação. Inicialmente, a obrigação de investir em $P \& D$ e a eficiência energética circunscreviam-se a cláusulas dos contratos de concessão, até a promulgação da Lei n. 9.991 (2000), que passou a ser considerada como o marco regulatório da P\&D para o setor. O marco regulatório sofreu várias mudanças e adendos desde o estabelecimento da obrigatoriedade do investimento

Entre 1998 a 2000, as empresas se familiarizaram com o Programa de P\&D ANEEL, imposto por força dos contratos de concessão e pautado na execução de projetos de pouca envergadura. 
Entre 2001e 2004, criaram-se as primeiras redes de cooperação envolvendo núcleos de pesquisa de ICTs e empresas de base tecnológica. Algumas concessionárias chegaram a se tornar incubadoras virtuais, em que empresas de base tecnológica, e núcleos de ICTs atuavam como uma extensão orgânica da P\&D através de uma relação de simbiose (Fernandino \& Oliveira, 2010). Com a Lei, os recursos de $P \& D$ não somente ficaram a cargo da administração governamental por meio de fundos setoriais, mas foram parcialmente transferidos para as empresas do setor. Destaque-se que a ANEEL aprovava os projetos de $\mathrm{P} \& \mathrm{D}$ antes que estes fossem iniciados. Os projetos precisavam ser submetidos pelas empresas à apreciação do órgão regulador em ciclos anuais, que os julgava como $P \& D$ ou não, consoante os seguintes critérios: resultados do projeto (benefícios públicos); qualidade da proposta; e qualificação da equipe executora (ANEEL, 2001). Após a finalização destes, a ANEEL podia fiscalizá-los sob as óticas da prestação de contas e do atingimento dos resultados tecnológicos. Caso o órgão regulador encontrasse problemas nesses componentes, poderia glosar o projeto ou multar as concessionárias. Não obstante, o programa somente permitia o uso de recursos em projetos de pesquisa básica, aplicada e desenvolvimento experimental.

O programa foi marcado por uma diminuição no montante de recursos devido à criação da EPE, entre 2004 e 2007. Nesse momento, o processo de P\&D do setor quase foi extinto pelo Ministério de Minas e Energia (MME) através da MP 144, o que não ocorreu devido a uma forte mobilização de atores, indicando a importância do Programa na criação de capacidades tecnológicas. Para as empresas, o que começou como uma imposição legal no Estágio 1, passou a ter lugar nas rotinas operacionais e na inserção em interesses estratégicos. Portanto, a partir deste estágio, além do efeito imposto, ganhou importância o efeito incitação. Nesse período, as Leis 10.848 e 11.465 alteraram novamente os percentuais de aplicação direta de $\mathrm{P} \& \mathrm{D}$ pelas empresas (Tabela 1).

Tabela 1

Percentual de Aplicação Direta das Empresas no P\&D da ANEEL (\% da ROL)

\begin{tabular}{|c|c|c|c|c|}
\hline \multirow[b]{2}{*}{ Segmento } & \multicolumn{2}{|c|}{ Lei 10.848 (2004) } & \multicolumn{2}{|c|}{ Lei 11.465 (2007) } \\
\hline & $\begin{array}{c}\text { Vigência: } 15 / 03 / 2004 \\
\text { a 31/12/2005 }\end{array}$ & A partir de $1 \% 01 / 2006$ & $\begin{array}{c}\text { Vigência: } 28 / 03 / 2007 \\
\text { a 31/12/2010 }\end{array}$ & A partir de $1 \% 01 / 2011$ \\
\hline Distribuição & 0,2 & 0,3 & 0,20 & 0,3 \\
\hline Geração & 0,4 & 0,4 & 0,40 & 0,4 \\
\hline Transmissão & 0,4 & 0,4 & 0,4 & 0,4 \\
\hline
\end{tabular}

Essas transformações forçaram a necessidade de readaptação do marco regulatório. Nesse período, foi realizado um trabalho de avaliação do Programa da ANEEL, da Pesquisa de Resultados do Programa de Pesquisa e Desenvolvimento para as Empresas do Setor Elétrico (PRPED), com resultados que indicaram a criação de capacidades tecnológicas, a substituição de produtos importados e a redução de gaps tecnológicos para as empresas respondentes (Machado, Salles-Filho, Brittes, Corder, \& Boer, 2008).

O ano de 2008 se caracterizou por um novo marco regulatório, no qual os projetos de P\&D\&I das empresas de energia elétrica não mais precisariam ser aprovados ex-ante pela ANEEL. Isto é, o órgão regulador apenas julgaria o mérito técnico-científico destes após sua conclusão (ex-post). Com isso, houve aumento do risco regulatório para as empresas, que passaram a executar projetos sem receber anuência prévia da ANEEL. Os critérios de avaliação ex-post do mérito técnico-científico dos projetos correspondiam a: originalidade do projeto, aplicabilidade, relevância e razoabilidade de custos (ANEEL, 2008a). A originalidade é o grau de novidade do projeto, enquanto a aplicabilidade representa sua importância e abrangência no mercado. A relevância julga o mérito científico do projeto em termos 
científicos, tecnológicos, econômicos e socioambientais, ao passo que a razoabilidade de custos mensura o retorno sobre o investimento.

No manual de 2008, houve avanços relevantes relacionados ao modelo de P\&D\&I adotado pela ANEEL, pois o Programa passou também a contemplar investimentos em projetos voltados para a consecução de cabeças-de-série, lotes pioneiros de protótipos e a introdução destes no mercado. Com as diretrizes do marco de 2008, as empresas podiam ir além do desenvolvimento experimental, isto é, estavam autorizadas a usar recursos do Programa para produzir e testar protótipos em escalas maiores em seus parques de ativos, bem como promover atividades de marketing voltadas ao lançamento do produto no mercado. Além disto, a ANEEL permitiu às concessionárias transferirem tecnologias para a indústria e auferirem receitas na forma de royalties com a comercialização dos produtos no mercado. Nesse estágio do Programa, iniciaram-se licenciamentos tecnológicos entre empresas de energia e universidades (proprietárias da tecnologia), e fabricantes fornecedores (licenciados).

As várias alterações sofridas no marco regulatório indicam instabilidade, percebida através das frequentes readequações de percentuais de investimentos, critérios de avaliação e timing de fiscalização dos projetos (ex-ante e ex-post). $\mathrm{O}$ conjunto dessas mudanças introduziu vantagens e dificuldades à execução da $\mathrm{P} \& \mathrm{D}$ ao longo dos anos para as empresas. As vantagens principais remontam-se à possibilidade de aplicarem os resultados dos projetos em seu parque de ativos, a criação de capacidades tecnológicas, redução de alguns gaps estruturais e o recebimento de royalties mediante a transferência de tecnologia para a indústria. No tocante às desvantagens, o marco regulatório trouxe custos de conformidade para as empresas e aumento do risco regulatório.

\section{PiTech: abordagem metodológica e aplicação da ferramenta}

A fim de se reduzir o risco regulatório sem detrimento dos interesses empresariais do investidor, foi criada a PiTech, que é uma ferramenta computacional concebida a partir da metodologia multicritério de avaliação, com efetiva possibilidade de mitigação de riscos regulatórios. A PiTech é aplicável tanto para empresas de energia que fazem inovação dentro do Programa da ANEEL, quanto para outros setores cuja inovação seja regulada. O fator motivador do desenvolvimento da metodologia e ferramenta foi o marco legal de 2008, responsável por aumentar substancialmente o risco regulatório nas empresas de energia, ao lhes transferir totalmente a decisão de quais projetos fazer em P\&D\&I, sem qualquer envolvimento ex-ante da Agência. Com o desenvolvimento da PiTech, vários atores (analistas, técnicos e engenheiros) podem ser simultaneamente envolvidos no processo de avaliação ex-ante dos projetos na empresa, tornando a mensuração do risco mais objetiva e menos dependente de um só ator. Uma das características da PiTech é que o participante apenas avalia os projetos em dimensões que melhor conhece, o que permite caracterizar melhor cada aspecto envolvido na avaliação.

A ferramenta é composta por quatro módulos, a saber: (a) módulo de acesso, autenticação e autorização; (b) módulo de infraestrutura e configurações; (c) módulo de operação, análise e avaliação multicritério; (d) módulo de pontuações e relatórios gerenciais.

A PiTech pressupõe diferentes níveis de agregação para cadastrar e avaliar os projetos. No módulo de infraestrutura e configurações, definem-se temas tecnológicos ou linhas de pesquisa no primeiro nível de agregação, como redes inteligentes. No próximo nível, os analistas de P\&D cadastram subtemas, os quais especificam os projetos de pesquisa. No caso de redes inteligentes, cabem projetos (ou subtemas) relacionados a medidores eletrônicos ou dispositivos inteligentes de controle de demanda residencial e assim por diante. De fato, esses subtemas são o objeto da avaliação multicritério em si, uma vez que a eles são alocados critérios, pontuações e pesos.

Após o cadastro de temas e subtemas, os analistas de P\&D determinam $n$ dimensões $\left(D_{n}\right)$, os $m$ respectivos critérios de avaliação $\left(C_{m}\right)$ e os pesos de ponderação, sendo que estes últimos são uma função das dimensões de análise $\left(p\left(D_{n}\right)\right)$. O conjunto das definições de temas, subtemas, dimensões e critérios formam um Estudo. 
A PiTech foi apresentada à Empresa, e teve suas dimensões, critérios e pesos definidos em reuniões com as várias áreas envolvidas no seu processo de $\mathrm{P} \& \mathrm{D} \& \mathrm{I}$, seguindo um protocolo exógeno à ferramenta, que considerou os elementos pertinentes à estratégia de inovação do grupo vis a vis suas estratégias corporativas. Destaque-se que seria possível desenvolver toda esta discussão de dimensões, critérios e pesos como outro Estudo, anterior ao que é a análise ex-ante dos projetos propriamente dita, apenas para tais definições que servem de calibração para uso da ferramenta pelos avaliadores dos projetos; neste caso, as linhas de pesquisa seriam as dimensões de análise, os temas seriam os critérios de cada dimensão, e, os subtemas, os pesos de cada critério. Isso, não feito dessa maneira, uma vez que já havia no grupo empresarial um posicionamento sólido e maduro a respeito de tópicos de avaliação de projetos de $\mathrm{P} \& \mathrm{D}$, oriundo de vários anos de experiência na $\mathrm{P} \& \mathrm{D}$ ANEEL, com a realização de mais de cem projeto em cerca de dez anos.

Calibrada a ferramenta, ela foi aplicada na avaliação de 19 projetos de P\&D\&I planejados em 2010, totalizando R \$ 61 milhões. A aplicação da PiTech numa carteira de projetos única não significa que a análise dos resultados obtidos seja mono-case, uma vez que o case apresentado neste trabalho refere-se à análise de 19 projetos de $\mathrm{P} \& \mathrm{D}$, completamente formatados e definidos, com todos os seus respectivos requisitos técnicos, econômicos, administrativos e regulatórios, em projetos da ordem de $\mathrm{R} \$$ 3,8 milhões cada. Também, 15 avaliadores, entre colaboradores de alto nível da organização, avaliaram cada projeto. Ademais, essa carteira é muito relevante em número de projetos e em montante investido, pois, do total de recursos aplicados em P\&D ANEEL no Setor Elétrico, o Grupo Empresarial objeto da análise responde por cerca de $10 \%$ em valor, e somente essa carteira representa cerca de $3 \%$ do valor total então investido no P\&D ANEEL.

Neste estudo, os analistas responsáveis determinaram as dimensões operacional, regulatória e mercadológica para análise. Em cada dimensão, foram elencados critérios homogêneos, medidos por escalas de pontuação (Tabela 2).

Tabela 2

Dimensões, Critérios e Escalas de Pontuação

\begin{tabular}{|c|c|c|c|}
\hline $\begin{array}{l}\text { Dimensão de } \\
\text { análise }\end{array}$ & Tipo de risco & Critérios & Escala de pontuação \\
\hline \multirow[t]{4}{*}{ Operacional } & \multirow[t]{4}{*}{ Tecnológico } & Arranjo executivo & $\begin{array}{l}\text { (1) baixo reconhecimento do arranjo; (2) moderado } \\
\text { reconhecimento do arranjo; (3) alto } \\
\text { reconhecimento do arranjo }\end{array}$ \\
\hline & & Qualidade da equipe & $\begin{array}{l}\text { (1) baixa qualidade da equipe; (2) média qualidade } \\
\text { da equipe; (3) alta qualidade da equipe }\end{array}$ \\
\hline & & Logística de realização & $\begin{array}{l}\text { (1) baixa logística de realização; (2) moderada } \\
\text { logística de realização; (3) alta logística de } \\
\text { realização }\end{array}$ \\
\hline & & $\begin{array}{l}\text { Disponibilidade } \\
\text { tecnológica }\end{array}$ & $\begin{array}{l}\text { (1) baixa disponibilidade tecnológica; (2) } \\
\text { moderada disponibilidade tecnológica; (3) alta } \\
\text { disponibilidade tecnológica }\end{array}$ \\
\hline \multirow[t]{4}{*}{ Regulatória } & \multirow[t]{4}{*}{ Regulatório } & Originalidade & $\begin{array}{l}\text { (1) inadequada; (2) insuficiente; (3) aceitável (4) } \\
\text { boa; (5) excelente }\end{array}$ \\
\hline & & Aplicabilidade & $\begin{array}{l}\text { (1) inadequada; (2) insuficiente; (3) aceitável (4) } \\
\text { boa; (5) excelente }\end{array}$ \\
\hline & & Relevância & $\begin{array}{l}\text { (1) inadequada; (2) insuficiente; (3) aceitável (4) } \\
\text { boa; (5) excelente }\end{array}$ \\
\hline & & $\begin{array}{l}\text { Razoabilidade de } \\
\text { custos }\end{array}$ & $\begin{array}{l}\text { (1) inadequada; (2) insuficiente; (3) aceitável (4) } \\
\text { boa; (5) excelente }\end{array}$ \\
\hline
\end{tabular}


Tabela 2 (continuação)

\begin{tabular}{llll}
\hline $\begin{array}{l}\text { Dimensão de } \\
\text { análise }\end{array}$ & Tipo de risco & Critérios & Escala de pontuação \\
\hline Mercadológica & Mercado & Imagem da empresa & $\begin{array}{l}\text { (1) baixa contribuição para a imagem; (2) } \\
\text { moderada contribuição para a imagem; (3) alta } \\
\text { contribuição para a imagem }\end{array}$ \\
\cline { 2 - 3 } & Novos negócios & $\begin{array}{l}\text { (1) baixa contribuição para novos negócios; (2) } \\
\text { moderada contribuição para novos negócios; (3) } \\
\text { alta contribuição para novos negócios }\end{array}$ \\
\cline { 2 - 3 } & Resultados & $\begin{array}{l}\text { (1) baixo resultado econômico-financeiro; (2) } \\
\text { moderado resultado econômico-financeiro; (3) alto } \\
\text { resultado econômico-financeiro }\end{array}$ \\
& &
\end{tabular}

A dimensão operacional é representada por critérios técnicos que medem a capacidade de execução dos projetos e o risco tecnológico. Assim, o critério arranjo executivo avalia o reconhecimento de parceiros externos do projeto em nível nacional. O critério qualidade da equipe avalia a capacidade executiva da equipe parceira. A logística de realização mede a factibilidade do projeto em termos de cronograma, etapas e recursos. A disponibilidade tecnológica analisa gargalos tecnológicos, isto é, os caminhos críticos do projeto.

Os critérios da dimensão regulatória compreendem a avaliação de mérito técnico-científico, presentes no manual de 2008 da ANEEL, e componentes do risco regulatório já conhecidos: originalidade, aplicabilidade, relevância e razoabilidade de custos.

Os critérios da dimensão mercadológica avaliam tanto o risco de mercado quanto os retornos trazidos pelo projeto. $\mathrm{O}$ critério imagem da empresa analisa os retornos institucionais relativos à responsabilidade socioambiental da organização. O critério novos negócios capta expectativas de demanda setorial para novos produtos, e o critério resultado avalia o retorno econômico-financeiro do negócio.

Um elemento muito relevante nesse aspecto da ferramenta é o estabelecimento dos pesos devido a seu impacto na análise, uma vez que eles escalam a pontuação dos critérios, cuja soma tem uma relação inversa à medida dos três riscos: quanto maior a pontuação, menor o risco.

Embora os critérios estejam associados à sua respectiva dimensão, eles também podem ser avaliados no âmbito das outras duas dimensões restantes. Para estes dois últimos casos, eles recebem pesos menores (Tabela 3). O critério originalidade, que possui peso máximo (igual a 10) na dimensão regulatória, também é avaliado sob as perspectivas mercadológica e operacional com pesos inferiores (iguais a 4 e 2 , respectivamente). 
Tabela 3

\section{Pesos dos Critérios por Dimensão de Análise}

\begin{tabular}{|c|c|c|c|c|c|c|c|c|c|c|c|}
\hline Dimensão & 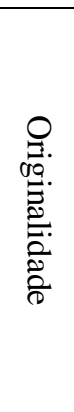 & 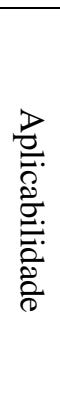 & $\begin{array}{l}\frac{\partial}{0} \\
\frac{0}{2} \\
2 \\
\stackrel{2}{2} \\
\frac{2}{2}\end{array}$ & 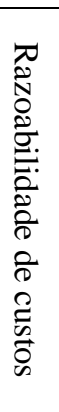 & 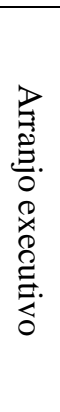 & 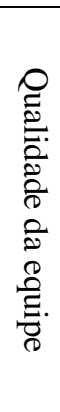 & 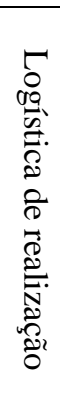 & 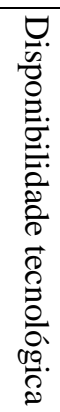 & 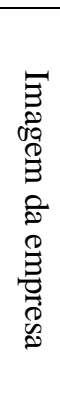 & $\begin{array}{l}z \\
0 \\
0 \\
0 \\
0 \\
\overrightarrow{0} \\
0 \\
0 \\
0 \\
0 . \\
0 \\
0\end{array}$ & 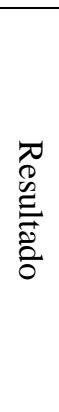 \\
\hline Regulatória & 10 & 10 & 10 & 10 & 4 & 6 & 2 & 2 & 2 & 2 & 4 \\
\hline Mercadológica & 4 & 4 & 4 & 4 & 4 & 4 & 4 & 4 & 10 & 10 & 10 \\
\hline Operacional & 2 & 4 & 2 & 4 & 10 & 10 & 10 & 10 & 2 & 4 & 4 \\
\hline
\end{tabular}

Os pesos foram obtidos de um trabalho exógeno à ferramenta, através de reuniões de trabalho com os avaliadores e outros envolvidos, como fatores que permitiam a cada analista envolvido no processo escalar (no sentido de impor com mais importância na ponderação da análise) os critérios de sua competência técnica e decisória, claro que, simultaneamente, implicando seus respectivos riscos. Objetivamente, não há um raciocínio analítico que resulte nos pesos apresentados. Trata-se de um mapeamento heurístico, que incorpora a experiência e o nível de aversão ao risco de cada avaliador.

O Estudo dos 19 projetos de P\&D foi realizado por uma amostra de distribuição normal de 15 colaboradores da empresa (técnicos, engenheiros e analistas de P\&D), os quais avaliaram apenas projetos e dimensões conhecidos e vinculados às suas áreas de atuação.

A pontuação de cada projeto $P$ por dimensão de análise consiste no valor $x$ atribuído a cada um dos 11 critérios definidos e ponderado pelos pesos $p\left(D_{n}\right)$, considerando-se o número $k$ de avaliadores da dimensão em questão. Assim:

$$
P=\sum_{k=1}^{y} \sum_{m=1}^{11} C_{m k} \cdot x \cdot p\left(D_{n}\right) \text {, tal que } x \in \mathrm{N}, \mathrm{n}=\{1,2,3\} \text { e } k \leq y .
$$

As pontuações são convertidas em uma escala de 1 a 100 por interpolação, ou seja, à maior pontuação atribui-se 100 e assim sucessivamente. Com base na pontuação obtida por dimensão, a PiTech também aloca os projetos em áreas de interesses, que representam as distintas combinações das três dimensões de análise (Figura 1).

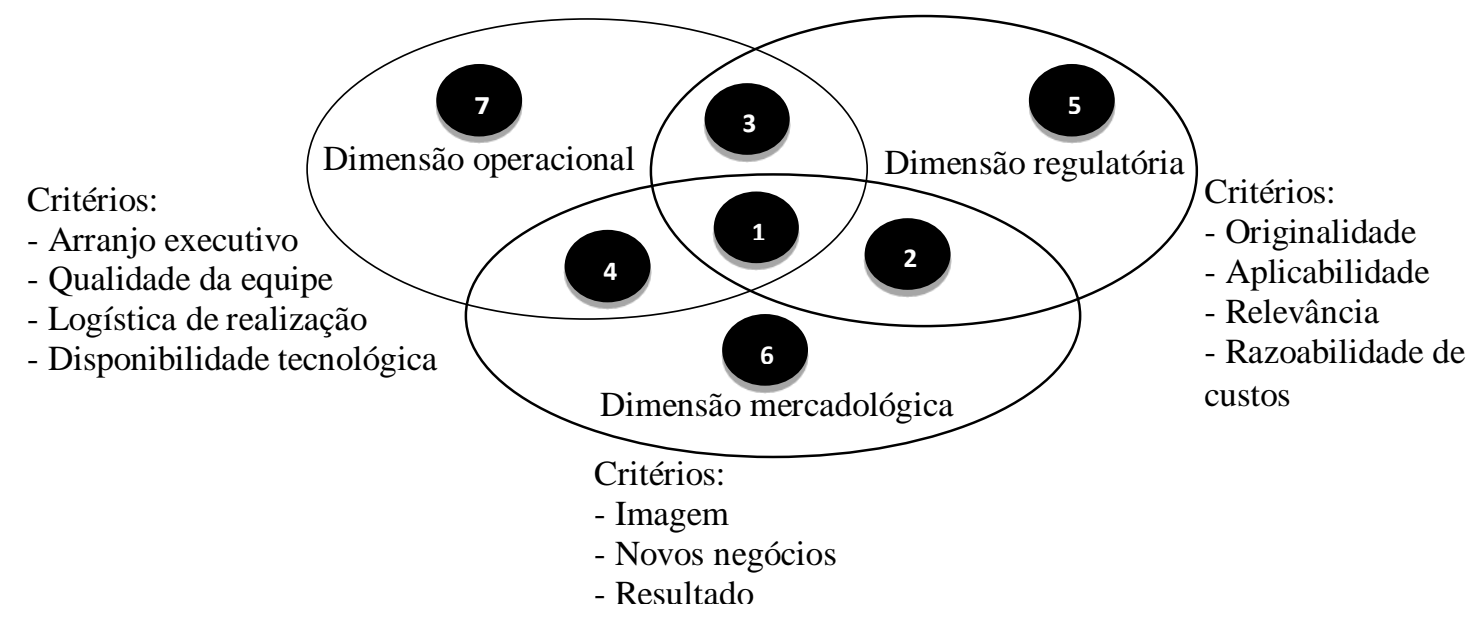

Figura 1. Sete Áreas de Interesse da PiTech 
Por exemplo, os projetos lotados na área 5 apresentam maior pontuação na dimensão regulatória em relação à mercadológica e à operacional. Projetos com pontuações equivalentes em duas ou três dimensões são alocados nas áreas de intersecção de 1 a 4; no caso de duas pontuações equivalentes entre as dimensões, é necessário essas serem maiores que a terceira pontuação. A distribuição da carteira em áreas faz-se fundamental para a empresa identificar se o projeto em avaliação atende a seus interesses, ao mesmo tempo em que cumpre os requisitos operacionais e os da ANEEL. Não obstante, a alocação também ajuda a distribuidora a decidir se executará o projeto com recursos próprios ou com os do Programa, estes últimos sujeitos ao risco regulatório. O resultado final da avaliação, expedido pelo módulo de pontuações e relatórios gerenciais, consiste na apresentação de uma lista formada pelo ranking geral, pela pontuação por dimensão de análise e pela média das três dimensões para cada projeto (Tabela 4).

Tabela 4

Lista de Preferências para a Carteira de Projetos de 2010

\begin{tabular}{cccccccc}
\hline $\begin{array}{c}\text { Posição } \\
\text { Ranking } \\
\text { Geral }\end{array}$ & $\begin{array}{c}\text { Título do } \\
\text { Projeto }\end{array}$ & $\begin{array}{c}\text { Total } \\
\text { Dimensão } \\
\text { Regulatória }\end{array}$ & $\begin{array}{c}\text { Total } \\
\text { Dimensão } \\
\text { Mercadológica }\end{array}$ & $\begin{array}{c}\text { Total } \\
\text { Dimensão } \\
\text { Operacional }\end{array}$ & $\begin{array}{c}\text { Média das } \\
\text { Dimensões }\end{array}$ & $\begin{array}{c}\text { Área de } \\
\text { Interesse }\end{array}$ & $\begin{array}{c}\text { Situação para } \\
\text { Contratação com } \\
\text { Recursos } \\
\text { ANEEL }\end{array}$ \\
\hline $\mathbf{1}$ & Projeto B & 90 & 90 & 90 & 90 & 1 & Aprovado \\
$\mathbf{2}$ & Projeto P & 70 & 70 & 70 & 70 & 1 & Aprovado \\
$\mathbf{3}$ & Projeto Y & 65 & 65 & 65 & 65 & 1 & Aprovado \\
$\mathbf{4}$ & Projeto K & 55 & 55 & 55 & 55 & 1 & Aprovado \\
$\mathbf{5}$ & Projeto S & 70 & 70 & 50 & 63 & 2 & Aprovado \\
$\mathbf{6}$ & Projeto N & 66 & 66 & 55 & 62 & 2 & Aprovado \\
$\mathbf{7}$ & Projeto H & 65 & 65 & 53 & 61 & 2 & Aprovado \\
$\mathbf{8}$ & Projeto A & 65 & 65 & 50 & 60 & 2 & Aprovado \\
$\mathbf{9}$ & Projeto R & 60 & 60 & 60 & 60 & 2 & Aprovado \\
$\mathbf{1 0}$ & Projeto C & 80 & 70 & 80 & 77 & 3 & Aprovado \\
$\mathbf{1 1}$ & Projeto I & 70 & 50 & 70 & 63 & 3 & Aprovado \\
$\mathbf{1 2}$ & Projeto F & 80 & 60 & 60 & 67 & 5 & Aprovado \\
$\mathbf{1 3}$ & Projeto G & 70 & 65 & 65 & 67 & 5 & Aprovado \\
$\mathbf{1 4}$ & Projeto L & 66 & 55 & 60 & 60 & 5 & Aprovado \\
$\mathbf{1 5}$ & Projeto O & 65 & 55 & 50 & 57 & 5 & Aprovado \\
$\mathbf{1 6}$ & Projeto Q & 60 & 52 & 52 & 55 & 5 & Aprovado \\
$\mathbf{1 7}$ & Projeto D & 30 & 40 & 40 & 37 & 4 & Reprovado \\
$\mathbf{1 8}$ & Projeto J & 28 & 40 & 30 & 33 & 6 & Reprovado \\
$\mathbf{1 9}$ & Projeto E & 24 & 22 & 40 & 29 & 7 & Reprovado \\
\hline
\end{tabular}

A PiTech monta o ranking geral fundamentando-se no seguinte ordenamento de preferências: priorizam-se para contratação pelo Programa da ANEEL todos os projetos situados na área 1, desde que a pontuação da dimensão regulatória seja superior a 50, assim como a nota média das três dimensões. Posteriormente, a PiTech prioriza projetos das áreas de interesse 2, 3 e 5, respectivamente, seguindo as mesmas regras de corte. Projetos alocados nas áreas 4, 6 e 7 são lotados no final da lista de preferências, não sendo aceitos para contratação pelo Programa da ANEEL. Na aplicação da ferramenta, os projetos $\mathrm{D}, \mathrm{J}$ e E foram reprovados, pois, além de não terem alcançado pontuações superiores a 50 , não foram lotados em áreas de interesse que contemplassem a dimensão regulatória. 
Como resultado, essa ferramenta de análise multivariada paramétrica mostrou-se muito flexível e propícia na ponderação dos critérios operacionais, mercadológicos e regulatórios combinados, permitindo que os tomadores de decisão da Holding de energia elétrica em questão avaliassem 19 projetos e optasse pelo investimento em 16, totalizando $\mathrm{R} \$ 61$ milhões em 2010, com riscos de glosa minimizados e concomitante aderência a interesses empresariais; 3 projetos, que representavam riscos de glosa de cerca de R \$11,4 milhões, eventual prejuízo levado diretamente a resultado, foram eliminados pela ferramenta. Dessa forma, a ferramenta cumpriu plenamente seu papel de ponderar aspectos tecnológicos, de mercado e regulatórios na análise ex-ante de projetos da P\&D no setor. Outro benefício da ferramenta foi permitir que avaliadores de várias áreas do grupo empresarial participassem da avaliação, de forma simples e efetiva, garantindo-se uma instância de decisão ponderada, ampla e focada em competência específica.

\section{PiTech: aspectos técnicos relevantes da ferramenta}

Dentro da conceituação estabelecida anteriormente, a PiTech opera baseada num protocolo sequencial de ações apresentados a seguir (Figura 2).

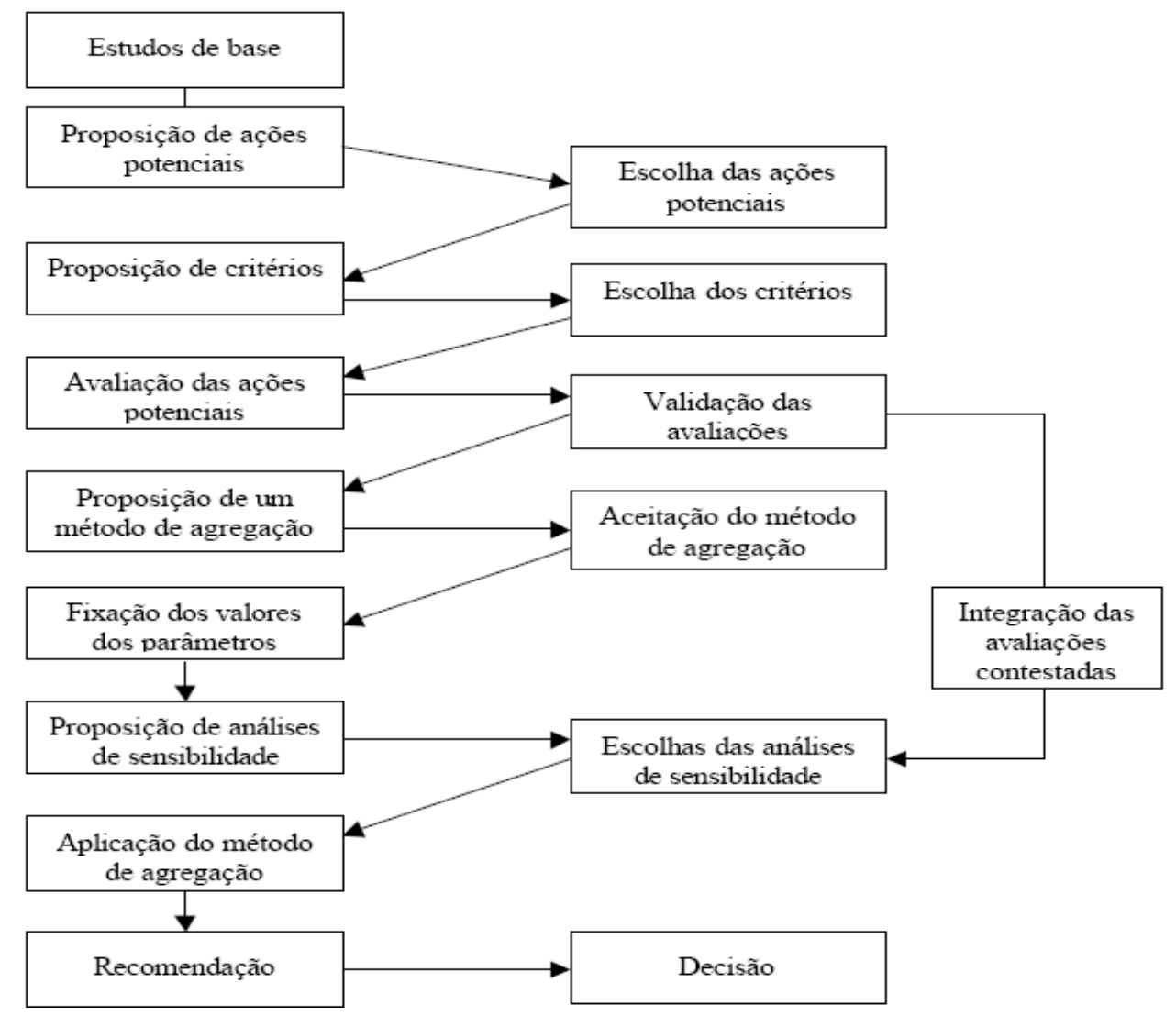

Figura 2. Processo Genérico Multicritério que Norteou a Implementação da PiTech (Vilas Boas, 2004)

Ela é uma Ferramenta Web formada por: (a) módulo de acesso, autenticação e autorização; (b) módulo de infraestrutura e configurações; (c) módulo de operação, análise e avaliação multicriterial; (d) módulo de cálculos estatísticos descritivos das pontuações e relatórios gerenciais variados. Ela emprega tecnologia Java, sobre navegadores IE8, Firefox 3, Google Chrome 4 e Safari 4, utiliza banco de dados e bibliotecas open source, e pode ser hospedada em datacenter ou rede de computadores. A PiTech fornece acesso e uso simultâneo por até 100 pessoas e permite múltiplas avaliações simultâneas. 


\section{Considerações Finais}

A P\&D do setor elétrico brasileiro passa, desde seu início, por uma trajetória instável, marcada pelas frequentes alterações no marco regulatório. Houve avanços nestes anos de vigência do Programa em termos de aumento de capacidades tecnológicas e da criação de redes de cooperação com empresas de base tecnológica e núcleos de ICTs. A maioria das empresas desenvolveu musculatura na gestão dos projetos do Programa. Contudo, a sistemática de avaliação usada pela ANEEL não avançou de forma a contemplar um ambiente propício de acomodação dos interesses entre regulador e empresas reguladas, visto que ainda não se ajusta às várias possibilidades de investimento em inovação no setor. Considerando-se que o setor elétrico é um monopólio natural estabelecido por barreira legal, com pouca motivação para inovar, essa acomodação de interesses é essencial.

A fim de prover as condições de acomodação de interesses entre regulador e empresa regulada e de mitigar o risco, foram desenvolvidas metodologia e ferramenta computacional para avaliar e priorizar projetos sob essas perspectivas, aplicada a uma carteira de 19 projetos, sendo que 16 foram contratados por apresentarem baixo risco regulatório, e de acomodar esse risco à factibilidade e ao interesse da empresa. A ferramenta é flexível o suficiente para permitir que sejam acrescentados novos critérios e dimensões. Porém, é essencial que os critérios sejam coerentes e robustos para representarem adequadamente as dimensões de análise.

A dimensão regulatória e a sua correlação com as dimensões mercadológica e operacional são chaves para avaliar projetos financiados com recursos do Programa da ANEEL, pois abarcam os critérios do manual de 2008 (originalidade, relevância, aplicabilidade e razoabilidade de custos), que compõem o risco regulatório.

Uma noção não óbvia, mas importante, obtida neste trabalho, é que se pode observar, pela figura 1 , a dificuldade que há para a ANEEL calibrar adequadamente uma régua que mensure, e premie ou puna projetos de forma adequada em todas as zonas de convergência de interesses dos atores no processo. Por default, o processo regulatório iniciou-se na Zona 5, e nas novas versões do Manual de P\&D ANEEL começa a adentrar a Zona 1, uma área de convergência compreensivelmente diminuta, pois une o interesse do gestor direto dos recursos (a empresa, que efetivamente os aplica e visa ao lucro), a uma maior viabilidade e a um menor risco de execução dos projetos (que é o substrato científicotecnológico de que o país dispõe para respaldar a execução da P\&D\&I, muito limitado no Brasil), e à gestão do Regulador (que deveria maximizar resultados sociais importantes dos recursos, que são de natureza pública). Ocorre que a inovação tecnológica do setor elétrico exige esforços em todas as sete áreas da figura 1. Embora a ANEEL seja, hoje, o ator sem dúvida mais engajado na inovação setorial, o sucesso de seu programa depende da solução de outras dificuldades decorrentes de estrutura e dinâmica setoriais, cuja discussão é complexa e está fora do escopo deste artigo. Contudo, apesar de seu recorrente exercício de adequação da régua-ANEEL de P\&D, o marco regulatório ainda carece de elementos de indução e mensuração dos esforços em cada uma das áreas; as chamadas para projetos estratégicos são, sem dúvida, uma ação positiva nesta direção (mormente na Zona 1), mas o caráter ainda monolítico da avaliação do Regulador, em particular agora, sem sua corresponsabilidade ex-ante, implica em restrições a resultados mais convincentes do programa. Contudo, a partir da metodologia aqui proposta, pode-se pensar quais métricas podem ser criadas para, em cada zona, fomentarem-se esforços profícuos que gerem ações coordenadas em nível de governo, indústria e setores de C\&T, que corroborem para um sucesso mais contundente e rápido do programa de P\&D ANEEL, como um todo.

Por fim, este trabalho abre algumas oportunidades de pesquisas futuras, como a proposição de novas dimensões de análise e a inclusão de novos critérios de mensuração, os quais também sejam aplicáveis à realidade de outros setores. 


\section{Referências}

Agência Nacional de Energia Elétrica. (2001, novembro). Manual do programa de pesquisa \& desenvolvimento. Brasília, DF: Autor.

Agência Nacional de Energia Elétrica. (2006). Manual do programa de pesquisa \& desenvolvimento. Brasília, DF: Autor.

Agência Nacional de Energia Elétrica. (2008b). ANEEL 10 anos. Brasília, DF: Autor.

Agência Nacional de Energia Elétrica. (2008a, maio). Manual do programa de pesquisa \& desenvolvimento. Brasília, DF: Autor.

Agência Nacional de Energia Elétrica. (2012). Manual do programa de pesquisa \& desenvolvimento. Brasília, DF: Autor.

Agência Nacional de Energia Elétrica. (2014). Lista de Projetos de P\&D. Recuperado de http://www.aneel.gov.br/area.cfm?idArea=75

Almeida, I. P. S., \& Ohayon, P. (2009, novembro). Relações entre regulação e inovação: restrições e incentivos. Anais do Seminário Latino-Iberoamericano de Gestión Tecnológica, Cartagena, Colômbia, 13.

Arrow, K. J. (1962). The economics implications of learning by doing. Review of Economic Studies, 29(3), 155-173. doi: 10.2307/2295952

Barba-Romero, S., \& Pomerol, J.-C. (1997). Decisiones multicriterio: fundamentos teóricos y utilización práctica. Alcalá de Henares, Madrid: Colección de Economia.

Bin, A., \& Salles-Filho, S. (2012). Science, technology and innovation management: contributions to a methodological framework. Journal of Technology Management and Innovation, 7(2), 73-86. doi: $10.4067 / \mathrm{s} 0718-27242012000200007$

Blind, K. (2012). The influence of regulations on innovation: a quantitative assessment for OECD countries. Research Policy, 41(2), 391-400. doi: 10.1016/j.respol.2011.08.008

Business Enterprise \& Regulatory Reform. (2008). Regulation and innovation: evidence and policy implications [Berr Economics Paper $\left.n^{\circ} 4\right]$. Department of Business Enterprise \& Regulatory Reform, United Kingdom.

Christensen, C. (2000). The innovator's dilemma: when technologies cause great firms to fail. New York: Harper Business.

Clark, K. B., \& Whellwright, S. C. (1993). Managing new product and process development: text and cases. New York: The Free Press.

Cooper, R. G. (2007). Managing technology development projects. IEEE Engineering Management Review, 35(1), 67-76. doi: 10.1109/EMR.2007.329141

Cooper, R. G., Edgett, S. J., \& Kleinschmidt, E. J. (2002). Optimizing the stage-gate process: what best practice companies are doing. Research Technology Management, 45(5), 21-27.

Fernandino, J. A., \& Oliveira, J. L. de (2010). Arquiteturas organizacionais para a área de P\&D em empresas do setor elétrico brasileiro. Revista de Administração Contemporânea, 14(6), 10731093. doi: 10.1590/S1415-65552010000700006 
Gilbert, R. J. (2006). Competition and innovation. Journal of Industrial Organization Education, 1(1), 1-23. doi: $10.2202 / 1935-5041.1007$

Henriksen, A. D., \& Traynor, A. J. (1999). A practical R\&D project-selection scoring tool. IEEE Transactions on Engineering Management, 46(2), 158-170. doi: 10.1109/17.759144

International Organization for Standardization. (2009a). ISO 31000 Risk management - Principles and guidelines [Standard]. Retrieved from https://www.iso.org/obp/ui/\#iso:std:iso:31000:ed-1:v1:en

International Organization for Standardization. (2009b). ISO 31010 Risk management - risk assessment techniques [Standard]. Retrieved from https://www.iso.org/obp/ui/\#!iso:std:51073:en

Keeney, R. L., \& Raiffa, H. (1976). Decisions with multiple objectives: preferences and value tradeoffs. New York: John Wiley \& Sons.

Laino, A. (2011). Innovation and monopoly: the position of Schumpeter [Paper $\mathrm{n}^{\circ}$ 35.321]. Uni München, Munich, Germany. Retrieved from http://mpra.ub.unimuenchen.de/35321/1/MPRA_paper_35321.pdf

Lei 9.991, de 24 de julho de 2000. (2000). Dispõe sobre realização de investimentos em pesquisa e desenvolvimento e em eficiência energética por parte das empresas concessionárias, permissionárias e autorizadas do setor de energia elétrica, e dá outras providências. Brasília, DF: Casa Civil.

Lei 10.848, de 14 de março de 2004. (2004). Dispõe sobre a comercialização de energia elétrica, altera as Leis nos 5.655, de 20 de maio de 1971, 8.631, de 4 de março de 1993, 9.074, de 7 de julho de 1995, 9.427, de 26 de dezembro de 1996, 9.478, de 6 de agosto de 1997, 9.648, de 27 de maio de 1998, 9.991, de 24 de julho de 2000, 10.438, de 26 de abril de 2002, e dá outras providências. Brasília, DF: Casa Civil.

Lei 11.465, de 28 de março de 2007. (2007). Altera os incisos I e III do caput do art. $1^{\circ}$ da Lei $n^{\circ} 9.991$, de 24 de julho de 2000, prorrogando, até 31 de dezembro de 2010, a obrigação de as concessionárias e permissionárias de serviços públicos de distribuição de energia elétrica aplicarem, no mínimo, 0,50\% (cinqüenta centésimos por cento) de sua receita operacional líquida em programas de eficiência energética no uso final. Brasília, DF: Casa Civil.

Leite, A., Albuquerque, A. B., \& Leal, M. J. (2007). Economia do conhecimento e empresas. Porto: Princípia Editora.

López, H. M. L., \& Almeida, A. T. de (2014). Utilizando PROMETHEE V para seleção de portfólio de projetos de uma empresa de energia elétrica. Production, 24(3), 559-571. doi: 10.1590/S010365132013005000045

Machado, F. V., Salles-Filho, S., Brittes, J. L. P., Corder, S. M., \& Boer, D. C. (2008, junho). Research, development and innovation in the electrical energy sector of Brazil: toward a tool for the support of the decision making process. Anais do Encontro da Associação Nacional de Pesquisa e PósGraduação em Ambiente e Sociedade, Brasília, DF, Brasil, 4.

Medida Provisória $N^{\circ}$ 144, de 10 de dezembro de 2003. (2003). Dispõe sobre a comercialização de energia elétrica, altera as Leis nos 5.655, de 20 de maio de 1971, 8.631, de 4 de março de 1993, 9.074, de 7 de julho de 1995, 9.427, de 26 de dezembro de 1996, 9.478, de 6 de agosto de 1997, 9.648, de 27 de maio de 1998, 9.991, de 24 de julho de 2000, 10.438, de 26 de abril de 2002, e dá outras providências. Brasília, DF: Casa Civil.

Mustafa, M., \& Al-Bahar, J. (1991). Project risk assessment using the analytic hierarchy process. IEEE Transactionson Engineering Management, 38(1), 46-52. doi: 10.1109/17.65759 
Nelson, R. R., \& Winter, S. G. (2005). Uma teoria evolucionária da mudança econômica. Campinas: Editora Unicamp.

Oliveira, M., \& Rozenfeld, H. (2011, setembro). Análise da gestão de portfólio de projetos de produtos com base nos conceitos da medição de desempenho: estudo de caso. Anais do Congresso Brasileiro de Gestão de Desenvolvimento de Produto, Porto Alegre, RS, Brasil, 8.

Organization for Economic Cooperation and Development. (2005). Oslo manual: guidelines for collecting and interpreting innovation data (3a ed.). Paris: Autor.

Pinto, H. Q., Jr., \& Fiani, R. (2002). Regulação econômica. In D. Kupfer \& L. Hasenclever (Orgs.), Economia industrial (pp. 515-543). Rio de Janeiro: Campus.

Pinto, M. S. L., \& Oliveira, R. L. (2004). Estratégias competitivas no setor elétrico brasileiro: uma análise dos interesses e expectativas dos atores da Chesf [Edição Especial]. Revista de Administração Contemporânea, 8, 131-155. doi: 10.1590/S1415-65552004000500008

Pompermeyer, M. L. (2009, junho). Desafios e perspectivas para a inovação tecnológica no setor de energia elétrica. Revista Pesquisa e Desenvolvimento da ANEEL, (3), p. 11.

Quadros, R. (2008, agosto). Aprendendo a inovar: padrões de gestão da inovação tecnológica em empresas industriais brasileiras. Anais da Conferência Nacional da Associação Nacional de Pesquisa \& Desenvolvimento das Empresas Inovadoras, Belo Horizonte, Minas Gerais, Brasil, 8.

Rothwell, R., \& Zegveld, W. (1988). Designing and implementing innovation policy. In D. Roessner (Org.), Government innovation policy: design, implementation, evaluation (pp. 19-36) London: The Macmillan Press.

Roy, B., \& Bouyssou, D. (1993). Aide multicritère á la décision: méthodsetcas. Paris: Economica.

Selltiz, C., Wrightsman, L. S., \& Cook, S. W. (1975). Métodos de pesquisa nas relações sociais. São Paulo: EPU e EDUSP.

Stigler, G. J. (1971). The theory of economic regulation. The Bell Journal of Economics and Management Science, 2(1), 3-21. doi: 10.2307/3003160

Trebing, H. M. (1984). Public utility regulation: a case study in the debate over effectiveness of economic regulation. Journal of Economic Issues, 18(1), 223-250.

Walz, R., Schleich, J., \& Ragwitz, M. (2008, September). How regulation influences innovation: an indicator based approach for the case of renewable energy technologies. Proceedings of the Globelics Conference, Mexico City, Mexico, 6.

\section{Dados dos Autores}

José Luiz Pereira Brittes

Rua Pedro Zaccaria, 1300, 13484-350, Limeira, SP, Brasil. E-mail: jose.brittes@fca.unicamp.br

Sergio L. M. Salles-Filho

Rua João Pandiá Calógeras, 51, 13083-870, Campinas, SP, Brasil. E-mail: sallesfi@ige.unicamp.br

Mariana Savedra Pfitzner

Av. Anchieta 200, 13015-904, Campinas, SP, Brasil. E-mail: mariana.savedra@ campinas.sp.gov.br 